IZA DP No. 7066

The Role of Parental Income over the Life Cycle:

A Comparison of Sweden and the UK

Anders Björklund

Markus Jäntti

Martin Nybom

December 2012 


\title{
The Role of Parental Income over the Life Cycle: A Comparison of Sweden and the UK
}

\author{
Anders Björklund \\ SOFI, Stockholm University \\ and IZA
}

Markus Jäntti

SOFI, Stockholm University

Martin Nybom

SOFI, Stockholm University

\section{Discussion Paper No. 7066 \\ December 2012}

\author{
IZA \\ P.O. Box 7240 \\ 53072 Bonn \\ Germany \\ Phone: +49-228-3894-0 \\ Fax: +49-228-3894-180 \\ E-mail: iza@iza.org
}

\begin{abstract}
Any opinions expressed here are those of the author(s) and not those of IZA. Research published in this series may include views on policy, but the institute itself takes no institutional policy positions. The IZA research network is committed to the IZA Guiding Principles of Research Integrity.

The Institute for the Study of Labor (IZA) in Bonn is a local and virtual international research center and a place of communication between science, politics and business. IZA is an independent nonprofit organization supported by Deutsche Post Foundation. The center is associated with the University of Bonn and offers a stimulating research environment through its international network, workshops and conferences, data service, project support, research visits and doctoral program. IZA engages in (i) original and internationally competitive research in all fields of labor economics, (ii) development of policy concepts, and (iii) dissemination of research results and concepts to the interested public.
\end{abstract}

IZA Discussion Papers often represent preliminary work and are circulated to encourage discussion. Citation of such a paper should account for its provisional character. A revised version may be available directly from the author. 
IZA Discussion Paper No. 7066

December 2012

\title{
ABSTRACT \\ The Role of Parental Income over the Life Cycle: A Comparison of Sweden and the UK
}

\begin{abstract}
Research on intergenerational income mobility has shown stronger persistence between parental and offspring's income in the UK than in Sweden. We use similar data sets for the two countries to explore whether these cross-national differences show up already early in offspring's life in outcomes such as birth weight, grades at the end of compulsory school at age 16, height during adolescence, and final educational attainment. We do indeed find significant country differences in the association between parental income and these outcomes, and the associations are stronger in the UK than in Sweden. Therefore, we continue to investigate whether these differentials are large enough to account for a substantial part of the difference in intergenerational persistence estimates. We then conclude that the country differences in the intergenerational associations in birth weight and height are too weak to account for hardly any fraction of the UK-Sweden difference in intergenerational income mobility. For the more traditional human-capital variables grades and final education, however, our results suggest that the country differences can account for a substantial part of the difference in income persistence.
\end{abstract}

JEL Classification: J24

Keywords: intergenerational mobility, birth weight, height, human capital

Corresponding author:

Anders Björklund

Swedish Institute for Social Social Research (SOFI)

Stockholm University

SE-10691 Stockholm

Sweden

E-mail: anders.bjorklund@sofi.su.se

\footnotetext{
* We thank Jo Blanden, Peter Fredriksson, Libertad Gonzalez, Magne Mogstad and seminar and workshop participants at, CHESS and SOFI (Stockholm University), DIW and Free University (Berlin), IFAU (Uppsala), Oslo University, Universitat Autònoma de Barcelona, University of Chicago, University of Mannheim for useful comments. Financial support from Swedish Council of Social and Working Life Research (FAS) is gratefully acknowledged.
} 


\section{Introduction}

The literature on intergenerational earnings and income mobility (or its inverse transmission), which has developed since the early 1990s, has revealed some striking cross-national differences. ${ }^{1}$ The United States has, to the surprise of many observers, come out as the country with the strongest intergenerational transmission among developed countries, whereas the Nordic countries have come out as high-mobility countries. The estimates for the United Kingdom are more mixed, but generally reveal lower mobility than in the Nordic countries.

What are the underlying mechanisms behind these differences? Are they related to policy? And if policies matter, what are the most important ones? No doubt, it is a great challenge for research to find out what mechanisms account for these cross-country differences. The most popular theoretical framework in the economics literature - the so-called Becker-Tomes model $(1979,1986)-$ suggests that a number of quite different mechanisms can account for country differences. Solon's (2004) parameterization of this model points at four broad factors, namely (i) "mechanical" (for example, genetic) transmission of income-generating traits, (ii) the efficacy of investment in children's human capital, (iii) the earnings return to human capital, and (iv) the progressivity of public investment in children's human capital.

The Becker-Tomes model focuses on parental investment in the health and skills of their children. The model also takes into account how these investments interact with public-policy investments in the form of education and health-care systems. Our reading of the literature is that most scholars, who try to understand intergenerational income and earnings correlations, have a child-development focus of the type highlighted by the Becker-Tomes model. Studies focusing on the labor market as the scene that generates intergenerational correlations are less frequent. ${ }^{2}$ Yet, one of the factors that follow from the model is the earnings return to human capital - (iii) above - and we know that such returns vary widely across countries' labor markets.

Our contribution is to account for cross-national differences in intergenerational income correlations by examining the importance of family income in different phases of the offspring's life. We compare Sweden, a high-mobility

\footnotetext{
${ }^{1}$ See Solon (2002), Corak (2006), Jäntti et al. (2006), Björklund and Jäntti (2009), and Blanden (2013) for alternative cross-national surveys of intergenerational income and earnings estimates.

${ }^{2} \mathrm{An}$ interesting exception with focus on labor-market mechanisms is Corak and Piraino (2011), who examine intergenerational transmission of employers.
} 
country, with the United Kingdom, a country with relatively low mobility, to study at what stage during the life cycle that the country differences emerge. Do they show up already early in life so that parental income matters more for early childhood characteristics such as health and school performance in the UK compared to Sweden? Or do the country differences not appear until the offspring generation has reached the labor market?

We use the British Cohort Study (BCS) of children born in 1970 and Swedish register data to explore the role of parental income for (1) birth weight, (2) height at late teen ages, (3) grades at the end of compulsory school at age 16, (4) final educational attainment and (5) long-run earnings during adulthood. We start with (5), that is, we start by presenting comparable estimates of intergenerational income transmission for the two countries. Our estimates show that comparable intergenerational income elasticities and correlations are significantly higher in the UK than in Sweden; for sons the elasticities are 0.271 vs. 0.199 and the correlations are 0.227 vs. 0.119 ; for daughters the difference in elasticities is slightly higher but the difference in correlations slightly lower. These results are in conformity with those reported in the previous literature. ${ }^{3}$

Then we continue to explore whether these differentials show up already early in the life cycle in outcomes (1)-(4) mentioned above. We find that there are indeed significant country differences already early in the life cycle, and the associations are stronger in the UK than in Sweden. We then ask whether these differences are large enough to account for the differences in intergenerational income persistence that motivated our study. For this purpose, we perform a decomposition analysis of the intergenerational income elasticity that gives the covariance between parental income and the child outcomes as well as the earnings returns to the child outcome a role. We experiment with this decomposition and let the UK get the Swedish covariance (and vice versa) and the UK get the Swedish returns (and vice versa). This exercise - although mechanical in some respects - suggests that the country differences in birth-weight and height associations are not strong enough to account for hardly any fraction of the UK-Sweden difference in intergenerational income mobility. For grades and final education, on the other hand, we find that country differences in intergenerational associations can account for a substantial part of the difference

\footnotetext{
${ }^{3}$ See, e.g., Blanden et al. (2004) for the UK. As we explain below, we use income and earnings definitions to suit the UK data and as a consequence the Swedish estimates are not comparable to previous ones. In a companion paper, we compare the gradients in child outcomes with respect to parental education in Sweden and the UK using the same data sources (Björklund et al., 2012).
} 
in income mobility.

The paper proceeds as follows. Section 1 offers a short literature background. We explain our data in Section 2. Section 3 reports our estimates of intergenerational associations. In Section 4, we perform our decomposition analyses to investigate the importance of the various outcomes. We report some robustness checks in Section 5 and conclude in Section 6.

\section{Literature Background}

\section{Birth Weight}

A large recent literature, efficiently surveyed by Currie (2009), has shown that birth weight in general and low birth weight in particular are related to parental socio-economic status. There are several reasons to expect such an association. The quality of the nutritional intake during pregnancy is one obvious candidate explanation. Parents in higher socioeconomic groups may also be better informed about health-related hazards that impact on the growth of the fetus. Such mechanisms have come to be known as the "fetal origin hypothesis", associated with the British epidemiologist David J. P. Barker. In addition, one can expect that biological mechanisms (genetic inheritance) cause a relationship between parental socio-economic status and birth weight. The country's health care system might very well have an impact on how strong these mechanisms are. A more compensatory system for care of pregnant mothers may attenuate both the nature and nurture of these relationships.

Birth weight, in turn, has been shown to predict several later and adult outcomes. The literature surveyed by Currie is full of examples showing that birth weight predicts outcomes related to health, including mortality, but also cognitive and noncognitive skills and thus also labor market performance. These relationships may show up because of the specific health problems that are related to low birth weight. However, it is also possible that low birth weight have direct effects on the acquisition of skills. Parents' reactions to the problems related to the underlying health problems are also likely to affect the impact of early health problems on subsequent acquisition of skills. The same applies to the health-care and school systems in the country.

Much of the recent literature focuses on the issue whether the associations between parental resources and birth weight and between birth weight and adult outcomes are causal or not. For our purposes it is not a major concern 
whether the associations are causal or not. We treat this variable as an indicator of several traits that are related to parental income and own performance later in life. Our research question is cross-national: we ask whether parental income is more strongly related to this set of traits in one country than in another, and whether this set of traits is a stronger predictor of adult outcomes in one country than in another.

\section{Height in Adolescence}

As explained below, we have access to data on height measured at ages 16, 26 and 29 for the UK, and at age 18 for Sweden. Obviously, these height measures reflect the cumulative growth up to these ages. This means that the combined genetic and environmental factors that contribute to birth weight also affect our height measures. Indeed, Black et al. (2007) find not only strong associations between birth weight and height during adolescence, but also suggestive evidence of causal effects. But, in addition, our height measures are also sensitive to a number of environmental conditions experienced during childhood. In their thorough survey of height determinants, Case and Paxson (2008) emphasize that the period from birth to age 3 is considered as the postnatal period that is most critical to height. Nutritional needs are greatest at this point in life as is sensitivity to infections of different types. Such factors are, of course, likely to be related to family background and in ways that might differ across countries.

Case and Paxson also emphasize that conditions during childhood affect the timing of children's growth. The timing of the typical pubertal growth spurt has been found to be sensitive to the child's health conditions and therefore also to parental background. Case and Paxson demonstrate that the growth spurt comes earlier for children of high socio-economic background. Thus, at some stages during adolescence, the pubertal growth spurt tends to magnify height differences between economic classes. Observing height at different ages in adolescence across countries could therefore give misleading estimates of country differences. In our analysis below, we avoid this problem by not only comparing height at age 16 for the UK and age 18 for Sweden - the first ages at which we have data - but also complementing this analysis with results for height at ages 26 and 29 for the UK.

The bivariate correlation between height and labor market earnings is quite strong. Using US PSID data, Case and Paxson report that the observed difference of 4 inches in men's heights at the 25th and the 75th percentiles is asso- 
ciated with an expected earnings differential of 9.2 percent. Furthermore, this association is observed throughout the whole height distribution. Lundborg et al. (2009), using the same Swedish data source as we do in this study, find only somewhat weaker bivariate associations.

Case and Paxson and Lundborg et al. also explore the mechanisms behind this bivariate height-earnings association. Indeed, the candidate mechanisms are several and include self-esteem, social dominance and discrimination. It might also be that height captures omitted variables such as cognitive and noncognitive skills and strength. Case and Paxson find, using US and UK data, that most of the height-earnings association is eliminated when cognitive skills are controlled for, whereas Lundborg et al. find that physical strength is a more important underlying factor. Just as for birth weight, it is not crucial for our purposes whether height is important per se, or if it is an indicator of several underlying productivity traits.

\section{School Grades}

Our next mediating variable is grades at age 16 at the end of compulsory school. This variable has a straightforward motivation for our purposes: grades are strongly associated with parental resources and early predictors of adult outcomes. The grades at the end of compulsory school are particularly important since they determine access to both study fields and schools at the uppersecondary level. A common result from research about the predictive performance of such grades is that they not only capture cognitive skills as measured by typical test scores, but also noncognitive skills such as motivation and persistence (see, e.g., Borghans et al., 2011 for recent research).

\section{Final Education}

As compulsory school grades, final education is a key variable when trying to understand intergenerational income correlations. Parental and public investment in the human capital of children is a central transmission mechanism in the theoretical work of Becker and Tomes $(1979,1986)$. From the perspective of intergenerational mobility, it is also important to stress that final education captures both performance in school, as also measured by our grade variable, and the set of choices of further education made after compulsory school. A large literature in sociology (see, e.g., Erikson et al., 2005) has shown that family 
background has a strong influence on both school performance (primary social origin effects) and school choices (secondary social origin effects).

\section{Data, Sample Restrictions and Variable Definitions}

\section{Sources and Sample Restrictions}

The British Cohort Study (BCS) is a survey of all children born in England, Scotland and Wales in one particular week in April 1970. The BCS is a very rich data set with surveys performed right after birth and at ages 5, 10, 16, 26, 30, and 34 . The first sweep covered the births and families of about 17200 children. In the two last sweeps the number of observations fell to 11200 (in 2000) and 9600 (in 2004). With each sweep, the scope of enquiry has broadened from a strictly medical focus at birth to encompass physical and educational development during the child's growth, and later on economic and labor market outcomes as adults.

For Sweden we have access to register data from various sources, which have been merged by Statistics Sweden using unique personal identifiers. For intergenerational research purposes, this is a very flexible data source. In this study, we use the available information for Sweden to "mimic" the UK data set as closely as possible. Our main sample for Sweden consists of all who were born in the country in 1973. We restrict our analysis to this cohort since it is the first one for which birth-weight data are accessible. In short, a number of data sets are merged together in order to obtain our variables of interest: the Swedish census in 1985 is used to identify each child's rearing parents in the fall of this year; birth-weight data are obtained from the National Board of Health and Welfare (in Swedish, Socialstyrelsen); height data are obtained from the compulsory military enlistments tests administered by The Swedish National Service Administration (Pliktverket); and separate registers at Statistics Sweden provide data on compulsory school grades at age 16 (Arskurs-9 registret), final education of both parents and offspring (the Education Register, or Utbildningsregistret), and income and earnings based on tax declarations for both parents and offspring. 


\section{Variables}

Parental income. In the BCS data set, parental income is defined as "all earned and unearned income of both father and mother" in 1980 and 1986. Moreover, it refers to the income of present parents (i.e., not necessarily biological parents) and is measured before taxes. To mimic this variable with the Swedish data, we use a measure of total income that includes income before taxes from all sources except means-tested benefits and universal child benefits (sammanräknad inkomst). We use data from the years 1983 and 1989 for Sweden since we want to measure parental income at identical ages of the child. In order to take into account only the income of present parents, we define parental income for those adults who lived in the same household as the child according to the census in $1985 .{ }^{4}$

An important difference between the parental income data in the two countries is that the UK data are available only as discrete intervals of the income distribution. Thus, we are restricted to use the center of each of the respective intervals as the measure of parental income. Moreover, the top interval is not bounded from above and consequently there is no center for this interval. We therefore obtain a proxy for those in the top interval by calculating the median gross family income in this top interval according to the Luxemburg Income Study (LIS). To ensure comparability, we use the Swedish data on parental income in the same way, i.e., by dividing the data into corresponding intervals and using the center values. For the unbounded highest interval, we apply the actual median. These income measures are used in our main analyses, but we also conduct a sensitivity analysis with the Swedish data by comparing the main results based on intervals with results from using the actual data.

Offspring earnings. The BCS includes data on offspring labor earnings for ages 30 and 34. From the Swedish tax register we extract information on labor earnings (arbetsinkomst) for the same ages. We use the log of the average of these two annual earnings observations as our measure of long-run earnings.

For the UK, both income and earnings information refers to weekly data at the time of the interview, whereas Swedish data sets offer annual measures of

\footnotetext{
${ }^{4}$ This choice creates a slight discrepancy from the UK data, which defines present parents at each ages 10 and 16 of the child. We could have identified parents in both the 1980 and 1990 censuses but in that case the children would have been 17 years old in the latter year and some might have moved out of their parents' home. We could also have used the 1980 census but then the child would have been quite young compared to UK.
} 
income and earnings. We divide the Swedish numbers by 52 in order to show comparable data in our descriptive tables, which of course does not affect our estimates. More important are the potential differences in selection that come with these differing data definitions. In the UK data, an individual needs to record positive earnings in a given week to be included in the sample. In the Swedish data, an individual only needs to record positive earnings sometime during the year to be included. Our UK sample is therefore likely to be more selective with a lower share of individuals with intermittent labor-market behavior. We have considered testing our results' sensitivity to this by restricting the Swedish data to individuals with less signs of intermittency in their earnings data. However, we have not found a satisfactory way of implementing such a test.

To sum up, the income and earnings measures we end up using are not ideal. They are most certainly causing some attenuation bias in our estimated intergenerational associations since the parental income measure is an average of only two annual income observations. ${ }^{5}$ Further, we measure offspring's earnings a couple of years too early in order to minimize the so-called life-cycle bias, at least according to evidence for Sweden. ${ }^{6}$ This probably also contributes to some downward bias in our intergenerational income estimates. Our maintained assumption in this study is that these two sources of bias are of the same magnitude in the two countries. ${ }^{7}$

Birth weight. For the UK, the birth-weight data stem from the initial sweep of the BCS and are based on reports from hospitals. For the Swedish data set, the birth-weight variable is also obtained from hospital reports delivered to the National Board of Health and Welfare. In our econometric specifications, we

\footnotetext{
${ }^{5}$ See, e.g., Mazumder (2005) for an examination of the relationship between the number of annual observations and the bias due to transitory income variation.

${ }^{6}$ For Swedish cohorts born around 1950, Böhlmark and Lindquist (2006) show that annual earnings approximate lifetime earnings at around age 33. With similar data on cohorts born 1955-57, Nybom and Stuhler (2011) however show that the intergenerational elasticity of lifetime income is best approximated when using income of the offspring from somewhat older ages. There is no comparable evidence on this for the UK.

${ }^{7}$ Another issue is related to the fact that we choose to measure parental income at a specific age of the child and thus at different ages of the parents depending on the age of parents at child's birth. We therefore control for parental age throughout, and additionally assume that any remaining bias is similar in Sweden and the UK such that it does not affect our crosscountry comparisons. An alternative with perfect data would have been to use parental lifetime income.
} 
use as dependent variables birth weight in kilograms, log of birth weight and a dummy for low birth weight defined as less than 2500 grams.

Height. The UK height data stem from a professional medical examination of the survey respondents at age 16. For Sweden, we obtain information on height from data collected at the military enlistment that is compulsory for all Swedish men. Most men do these tests at age 18. Thus we cannot do this analysis for women. Because we measure height at different ages in the two countries, we standardize the variable when we use it as dependent variable in our regressions. As noted in the previous section, we also complement our analysis for the UK by looking at height data from ages 26 and 29 as a robustness check.

School grades. Comparing grades across countries is not unproblematic. In order to be able to include grades on a comparable basis, we transform each grade of selected subjects of every person into a percentile rank, and then take the average percentile rank across all subjects as each individual's grade measure. For the UK, we use the grades in the O-level (or CSE) examinations in the English language, English literature, mathematics, science, physics, chemistry, biology, history, geography, French, German and business studies. We have spliced together the O-levels and CSE according to the following ranking: (1) O level A, (2) O level B, (3) O level C or CSE 1, (4) O level D or CSE 2, (5) O level E or CSE 3, (6) CSE 4, (7) CSE 5, and (8) fail. ${ }^{8}$ We invert the scale so that higher grades get coded higher, and assign to each person for each subject the percentile that corresponds to the tabulated percentile at the grade he or she received. For Sweden, we use the grades at the end of compulsory school (i.e., at age 16 after nine years of compulsory schooling) in English, biology, physics, chemistry, technology, geography, history, religion, social studies and Swedish. We choose these subjects since they are taken by all students according to an identical curriculum. Next, we tabulate the distribution of grades for each subject and assign to each person the percentile rank of the grade they received. We then take the average of a person's rank across all subjects as our measure of their grade. This procedure has been used before, for example by Björklund et al. (2003), who studied the importance of family background for school performance in Sweden across time. We have experimented with variations of these procedures, and while the exact estimates vary, the qualitative conclusions we

\footnotetext{
${ }^{8}$ This splicing together of the grades for the UK was implemented for Björklund et al. (2012) after conversations with Jo Blanden and John Ermisch.
} 
reach do not. However, we must concede that the results with respect to the parental background gradient in grades are in some sense likely to be the least comparable, for the simple reason that the schooling institutions in Sweden and the UK differ. As an example, student tracking by field of study occurs at an earlier age in UK than in Sweden. Although this is on the one hand problematic for our analysis, it is on the other hand exactly these types of institutional differences that motivate our study and make the UK-Sweden comparison interesting.

Final education. Since educational systems often differ across countries it is not as straightforward how to use data on final education in cross-country studies as, e.g., data on income and earnings. In this paper, we apply the International Standard Classificaton of Education (ISCED) developed by UNESCO to order highest educational attainment into hierarchical categories. The ISCED was designed with the purpose to make educational levels internationally comparable. We have combined the two lowest categories into a single one, labelled as 2 in the result tables, since category 1 is nearly empty for the cohort we study. The Swedish data come from Statistics Sweden's education register. The UK data are self reported and we use the BCS wave from 2004. Thus, final education is measured at age 34 for the UK sample. ${ }^{9}$ For the offspring in the Swedish sample, we employ data on final education from 2007 , i.e., also when the subjects were 34 years old.

\section{Results}

\section{Intergenerational Income Associations}

Although the results from previous studies are our point of departure, we start by estimating new intergenerational measures (elasticities and correlations) on our own sample. Table 1 shows the associated descriptive statistics. UK parents are about one year younger when their income is measured, a rather small difference. For both countries, we note that the standard deviation of log of parental income is lower than the standard deviation of the log of offspring's earnings. This difference implies that our estimated intergenerational correlations will differ from our estimated intergenerational elasticities.

\footnotetext{
${ }^{9}$ For a few observations with missing data in 2004 , we instead used information from the year 2000 sweep.
} 


\begin{tabular}{|c|c|c|c|c|}
\hline & \multicolumn{2}{|c|}{ Sons } & \multicolumn{2}{|c|}{ Daughters } \\
\hline & Sweden & UK & Sweden & UK \\
\hline Log earnings, offspring & $\begin{array}{l}6.25 \\
(0.77)\end{array}$ & $\begin{array}{l}6.57 \\
(0.61)\end{array}$ & $\begin{array}{l}5.93 \\
(0.76)\end{array}$ & $\begin{array}{l}5.98 \\
(0.87)\end{array}$ \\
\hline Log income, parents & $\begin{array}{l}6.52 \\
(0.46)\end{array}$ & $\begin{array}{l}6.18 \\
(0.51)\end{array}$ & $\begin{array}{l}6.52 \\
(0.46)\end{array}$ & $\begin{array}{l}6.20 \\
(0.51)\end{array}$ \\
\hline Parental age & $\begin{array}{c}40.80 \\
(4.99)\end{array}$ & $\begin{array}{c}39.45 \\
(5.77)\end{array}$ & $\begin{array}{c}40.73 \\
(5.00)\end{array}$ & $\begin{array}{c}39.49 \\
(5.75)\end{array}$ \\
\hline Fraction with two parents & 0.88 & 0.93 & 0.87 & 0.93 \\
\hline $\mathrm{n}$ & 48424 & 3304 & 44414 & 3153 \\
\hline
\end{tabular}

Note: Table shows means with standard deviations within parentheses. We use weekly income and earnings, PPPadjusted to 2005 dollars. Swedish annual income and earnings are divided by 52 in order make the data comparable. We condition on offspring's earnings $>10$ dollars/week. Parental age (the mean of both parents) and fraction with two parents are measured at the time parental income is measured. The latter is for descriptive purpose only and not included in the regressions.

We report estimates of standard intergenerational associations in Table 2. Since there is age variation among parents, we have in every case controlled for parental age (and its square) both here and in the subsections below. ${ }^{10}$ As expected from previous research, the intergenerational income associations are lower for Sweden than for the UK. The standard errors are reasonably small, so the null hypothesis of equality across countries is strongly rejected. For men, the point estimates of the elasticities are .199 for Sweden and .271 for the UK, and the corresponding correlations - regressions with standardized income measures for both parents and offspring - are .119 and .227. The differences for women are of similar magnitude. As discussed above, all these estimates are downward biased but hopefully equally much for both countries' estimates.

In row 3 of Table 2, we also report estimates for a model that adds a quadratic term for the log of parental income (unstandardized). The estimates suggest that the functional form is not very different in the two countries. ${ }^{11}$ Thus, we stick to the simple linear framework to explore the cross-national differences in factors underlying intergenerational income persistence.

\footnotetext{
${ }^{10}$ Because we use cohort data, we do not have to control for offspring's age. Since we use family income for parents, we control for the average age of the two parents.

${ }^{11}$ An evaluation of the quadratic model shows that the elasticity is rising with parental income in both countries and for both genders. The difference in the elasticity between the countries is constant for daughters but rising with parental income for sons. In our decomposition analysis in Section 4, we ignore this different pattern for sons.
} 


\begin{tabular}{|c|c|c|c|c|c|c|}
\hline & \multicolumn{3}{|c|}{ Sons } & \multicolumn{3}{|c|}{ Daughters } \\
\hline & Sweden & UK & F-test & Sweden & UK & F-test \\
\hline Regression coef & $\begin{array}{l}0.199 \\
(0.008)\end{array}$ & $\begin{array}{l}0.271 \\
(0.021)\end{array}$ & $\begin{array}{c}4.5 \\
{[0.034]}\end{array}$ & $\begin{array}{l}0.179 \\
(0.008)\end{array}$ & $\begin{array}{l}0.329 \\
(0.030)\end{array}$ & $\begin{array}{c}31.2 \\
{[0.000]}\end{array}$ \\
\hline Correlation & $\begin{array}{l}0.119 \\
(0.005)\end{array}$ & $\begin{array}{l}0.227 \\
(0.017)\end{array}$ & $\begin{array}{c}29.4 \\
{[0.000]}\end{array}$ & $\begin{array}{l}0.108 \\
(0.005)\end{array}$ & $\begin{array}{l}0.193 \\
(0.018)\end{array}$ & $\begin{array}{c}22.8 \\
{[0.000]}\end{array}$ \\
\hline Quadratic (lin) & $\begin{array}{c}-0.432 \\
(0.114)\end{array}$ & $\begin{array}{c}-0.956 \\
(0.297)\end{array}$ & $\begin{array}{c}9.0 \\
{[0.003]}\end{array}$ & $\begin{array}{c}-0.375 \\
(0.118)\end{array}$ & $\begin{array}{c}-0.835 \\
(0.430)\end{array}$ & $\begin{array}{c}2.7 \\
{[0.103]}\end{array}$ \\
\hline (sq.) & $\begin{array}{l}0.050 \\
(0.009)\end{array}$ & $\begin{array}{l}0.101 \\
(0.024)\end{array}$ & & $\begin{array}{l}0.044 \\
(0.009)\end{array}$ & $\begin{array}{l}0.096 \\
(0.035)\end{array}$ & \\
\hline
\end{tabular}

Note: We use the average of the parents' age and its square as controls in the regression models in this and the subsequent tables. Standard errors are within parentheses and p-values within brackets.

\section{Birth Weight}

We estimate simple models with birth weight as dependent variable and the log of long-run parental income as independent variable. In the literature, different measures of birth weight have been used, for example, raw birth weight in kilograms, log of birth weight, a dummy indicator for low birth weight (typically less than 2.5 kilos), and fetal growth (defined as birth weight divided by weeks of gestation). Black et al. (2007) examine the explanatory power of these variables and report that log of birth weight provide the best fit for their outcome variables, which included adult earnings. ${ }^{12}$ Nevertheless, we report results for birth weight in kilos, the log of birth weight and low birth weight.

Panels A-C in Table 3 report sample descriptives. Here and in subsequent analysis of the other traits, we use the maximum sample size in the data set. In Section 5 below, we report sensitivity analysis based on balanced samples for all outcomes. We note that birth weight for the 1973 cohort in Sweden exceeds the birth weight for the 1970 cohort in the UK by around 180-210 grams. Otherwise the standard deviations are similar. Thus, not surprisingly, the prevalence of low birth weight is higher in the UK than in Sweden; around 6 percent compared to around 3 percent.

Estimates for birth weight and low birth weight, respectively, are shown in Panels A-C of Table 4. Our basic conclusions are robust with respect to the two measures, and also whether we standardize the variables or not. A first basic conclusion is that there is indeed a significant parental income gradient in birth weight for both sons and daughters, and in both countries. A second conclu-

\footnotetext{
${ }^{12}$ We note though that their conclusion refers to twin fixed-effects regressions.
} 


\section{Table 3 Descriptive Statistics for Outcome Samples}

\begin{tabular}{|c|c|c|c|c|c|}
\hline & & \multicolumn{2}{|c|}{ Sons } & \multicolumn{2}{|c|}{ Daughters } \\
\hline & & Sweden & UK & Sweden & UK \\
\hline \multirow[t]{4}{*}{ A. Birth weight) } & Birth weight & $\begin{array}{l}3.55 \\
(0.54)\end{array}$ & $\begin{array}{l}3.37 \\
(0.55)\end{array}$ & $\begin{array}{l}3.42 \\
(0.52)\end{array}$ & $\begin{array}{l}3.25 \\
(0.51)\end{array}$ \\
\hline & Log parental inc. & $\begin{array}{l}6.51 \\
(0.46)\end{array}$ & $\begin{array}{l}6.13 \\
(0.54)\end{array}$ & $\begin{array}{l}6.52 \\
(0.46)\end{array}$ & $\begin{array}{l}6.15 \\
(0.53)\end{array}$ \\
\hline & Parental age & $\begin{array}{c}40.83 \\
(5.02)\end{array}$ & $\begin{array}{c}39.09 \\
(5.88)\end{array}$ & $\begin{array}{c}40.73 \\
(4.99)\end{array}$ & $\begin{array}{c}39.29 \\
(5.87)\end{array}$ \\
\hline & $\mathrm{n}$ & 49875 & 5356 & 45838 & 5009 \\
\hline \multirow[t]{4}{*}{ B. Log birth weight } & Log birth weight & $\begin{array}{l}1.25 \\
(0.17)\end{array}$ & $\begin{array}{l}1.20 \\
(0.18)\end{array}$ & $\begin{array}{l}1.22 \\
(0.17)\end{array}$ & $\begin{array}{l}1.17 \\
(0.17)\end{array}$ \\
\hline & Log parental inc. & $\begin{array}{l}6.51 \\
(0.46)\end{array}$ & $\begin{array}{l}6.13 \\
(0.54)\end{array}$ & $\begin{array}{l}6.52 \\
(0.46)\end{array}$ & $\begin{array}{l}6.15 \\
(0.53)\end{array}$ \\
\hline & Parental age & $\begin{array}{l}40.83 \\
(5.02)\end{array}$ & $\begin{array}{l}39.09 \\
(5.88)\end{array}$ & $\begin{array}{l}40.73 \\
(4.99)\end{array}$ & $\begin{array}{l}39.29 \\
(5.87)\end{array}$ \\
\hline & $\mathrm{n}$ & 49875 & 5356 & 45838 & 5009 \\
\hline \multirow[t]{4}{*}{ C. Low birthweight } & Low birthweight & $\begin{array}{l}0.03 \\
(0.17)\end{array}$ & $\begin{array}{l}0.06 \\
(0.24)\end{array}$ & $\begin{array}{l}0.04 \\
(0.19)\end{array}$ & $\begin{array}{l}0.06 \\
(0.24)\end{array}$ \\
\hline & Log parental inc. & $\begin{array}{l}6.51 \\
(0.46)\end{array}$ & $\begin{array}{l}6.13 \\
(0.54)\end{array}$ & $\begin{array}{l}6.52 \\
(0.46)\end{array}$ & $\begin{array}{l}6.15 \\
(0.53)\end{array}$ \\
\hline & Parental age & $\begin{array}{c}40.83 \\
(5.02)\end{array}$ & $\begin{array}{c}39.09 \\
(5.88)\end{array}$ & $\begin{array}{c}40.73 \\
(4.99)\end{array}$ & $\begin{array}{c}39.29 \\
(5.87)\end{array}$ \\
\hline & $\mathrm{n}$ & 49875 & 5356 & 45838 & 5009 \\
\hline \multirow[t]{4}{*}{ D. Height } & Height & $\begin{array}{l}1.80 \\
(0.06)\end{array}$ & $\begin{array}{l}1.74 \\
(0.09)\end{array}$ & n.a. & n.a. \\
\hline & Log parental inc. & $\begin{array}{l}6.52 \\
(0.46)\end{array}$ & $\begin{array}{l}6.20 \\
(0.52)\end{array}$ & n.a. & n.a. \\
\hline & Parental age & $\begin{array}{l}40.81 \\
(5.01)\end{array}$ & $\begin{array}{c}39.91 \\
(5.76)\end{array}$ & n.a. & n.a. \\
\hline & $\mathrm{n}$ & 45851 & 2822 & n.a. & n.a. \\
\hline \multirow[t]{4}{*}{ E. Average grade } & Average grade & $\begin{array}{l}0.47 \\
(0.21)\end{array}$ & $\begin{array}{l}0.50 \\
(0.13)\end{array}$ & $\begin{array}{l}0.53 \\
(0.20)\end{array}$ & $\begin{array}{l}0.52 \\
(0.13)\end{array}$ \\
\hline & Log parental inc. & $\begin{array}{l}6.52 \\
(0.46)\end{array}$ & $\begin{array}{l}6.16 \\
(0.53)\end{array}$ & $\begin{array}{l}6.52 \\
(0.46)\end{array}$ & $\begin{array}{l}6.16 \\
(0.52)\end{array}$ \\
\hline & Parental age & $\begin{array}{c}40.82 \\
(5.01)\end{array}$ & $\begin{array}{c}39.70 \\
(5.82)\end{array}$ & $\begin{array}{c}40.71 \\
(4.98)\end{array}$ & $\begin{array}{c}39.69 \\
(5.82)\end{array}$ \\
\hline & $\mathrm{n}$ & 48915 & 4212 & 44988 & 4175 \\
\hline \multirow[t]{5}{*}{ F. Education } & 3 & 0.51 & 0.26 & 0.43 & 0.25 \\
\hline & 4 & 0.14 & 0.08 & 0.14 & 0.09 \\
\hline & 5 & 0.26 & 0.35 & 0.39 & 0.38 \\
\hline & Parental age & $\begin{array}{c}40.84 \\
(5.02)\end{array}$ & $\begin{array}{c}39.48 \\
(5.83)\end{array}$ & $\begin{array}{c}40.72 \\
(5.00)\end{array}$ & $\begin{array}{c}39.48 \\
(5.68)\end{array}$ \\
\hline & $\mathrm{n}$ & 48811 & 3277 & 44549 & 3575 \\
\hline
\end{tabular}

Note: Table shows means (with standard deviations within parentheses) of child outcomes and log parental income for the different outcome samples. Parental age (the mean of both parents) and fraction with two parents are measured at the time parental income is measured. Birth weight is measured in kilograms, low birth weight is an indicator for less than 2.5 kilograms. Height is in meters and education is measured as ISCED levels, with levels 1 and 2 merged into one (the omitted category). 
sion is that the associations are significantly stronger in the UK than in Sweden. Nonetheless, the magnitude of all the estimated intergenerational associations is quite low. For example, the highest coefficient reported in Panel B is .095 for UK daughters, and the correlation between the birth weight and the log of parental income is only .099.

\section{Height}

Panel D in Table 3 reports sample descriptives for our height samples. Because in the base case we measure height at age 16 for the UK and at age 18 for Swedish sons, it is natural that Swedish sons are taller than the UK sons in our data. Because of this difference in measurement, we must treat estimates of country differences based on unstandardized height with caution. Thus, we should pay most attention to the estimates denoted as correlations.

Panel D in Table 4 reports our estimates for age 16 in the UK. All single estimates are strongly significantly different from zero. Again, we also find a significant country difference with larger coefficients for the UK. Yet, the magnitude of the correlations between parental income and height is modest, at most .142 at age 16 in the UK. We have also estimated the same models on UK data for ages 26 and 29 with similar results; the results are available upon request.

\section{School Grades}

We report sample descriptives for our grade samples in Panel E of Table 3. The overall mean of the average percentile is slightly above 0.5 for daughters and slightly below for sons. This reflects a general and well-known gender gap in school performance. A difference between the countries, however, is that the standard deviation in grades is markedly higher in Sweden. This reflects the fact that the grade systems are different in the two countries; the variation is affected by the number of fields that are graded and by the number of steps for each graded field. Because of this difference, we focus on the results with standardized variables in Panel E of Table 4.

It is not surprising that all single parameters are strongly significantly different from zero. Interestingly, however, we also find significant country differences in the intergenerational transmission estimates, and again the UK ones are the largest for the standardized variables. 


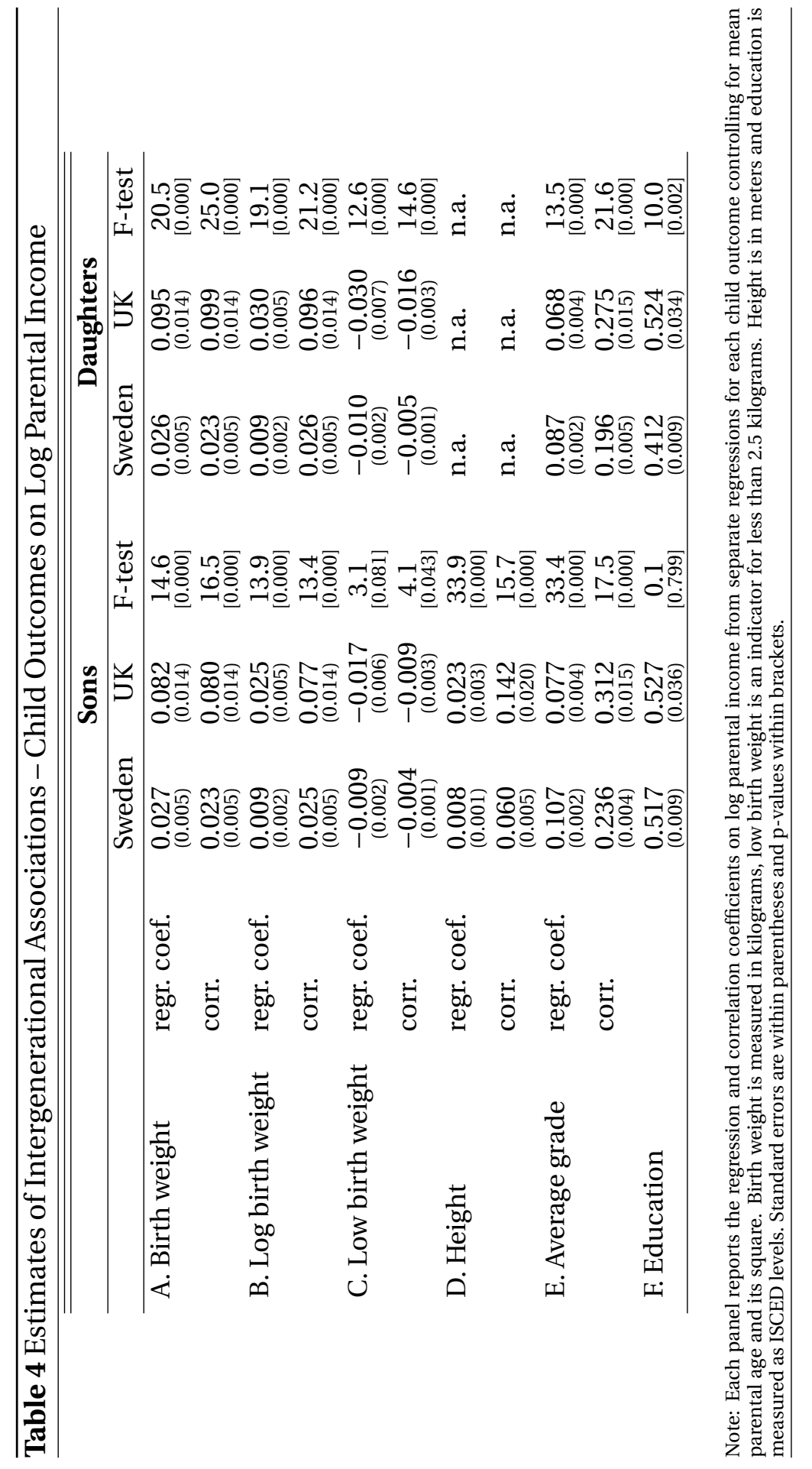




\section{Final Education}

Our basic education information is available in the form of levels of education. One option would be to transform these levels into years of schooling in order to estimate very simple models with years of schooling as dependent variable for both countries. However, we prefer to use the original data since the transformation from levels to years might create country-specific errors. Thus, we estimate ordered-probit models with the four ISCED levels as dependent variable (recall that we have combined levels 1 and 2).

We report sample descriptives in panel $\mathrm{F}$ in Table 3. The distribution of individuals across the five ISCED levels differs somewhat across the countries. This could both reflect institutional differences and the fact that the individuals in the UK sample are likely to be less representative of the population. The mode for the UK sample is level 5, whereas the mode for the Swedish sample is level 3. This reflects the classification of the standard post-compulsory (high school) track in each country. We also note a quite clear gender gap in educational attainment in Sweden (to the advantage of women), but not in the UK.

We report our estimates in panel $\mathrm{F}$ of Table 4, and offer a visual presentation of the implications of the estimates in Figure 1. We have used standardized parental income. As expected, the parental income gradients in educational attainment are significantly different from zero in both countries. As for the other traits, the point estimates of the intergenerational transmissions coefficients are higher for the UK than for Sweden. However, in this case only the difference among daughters is significantly different from zero. When looking at the visual presentation in Figure 1, we can see that the different gradients are most evident between Swedish and UK offspring at levels 2 and 3. The visual impression is quite similar for men and women, even if the difference among men is insignificant.

\section{Interpretation of the Results}

So far we have found that there is indeed a UK-Sweden difference in the association between parental income and child outcomes already early in life. But how important are these differences? Can they possibly account for a considerable part of the country difference in intergenerational income associations that we reported in Section 3? Or is it more likely that returns to the productive traits that we have examined account for the cross-national differences? To 


\section{Figure 1 Regression of Offspring Final Education on Log Parental Income}

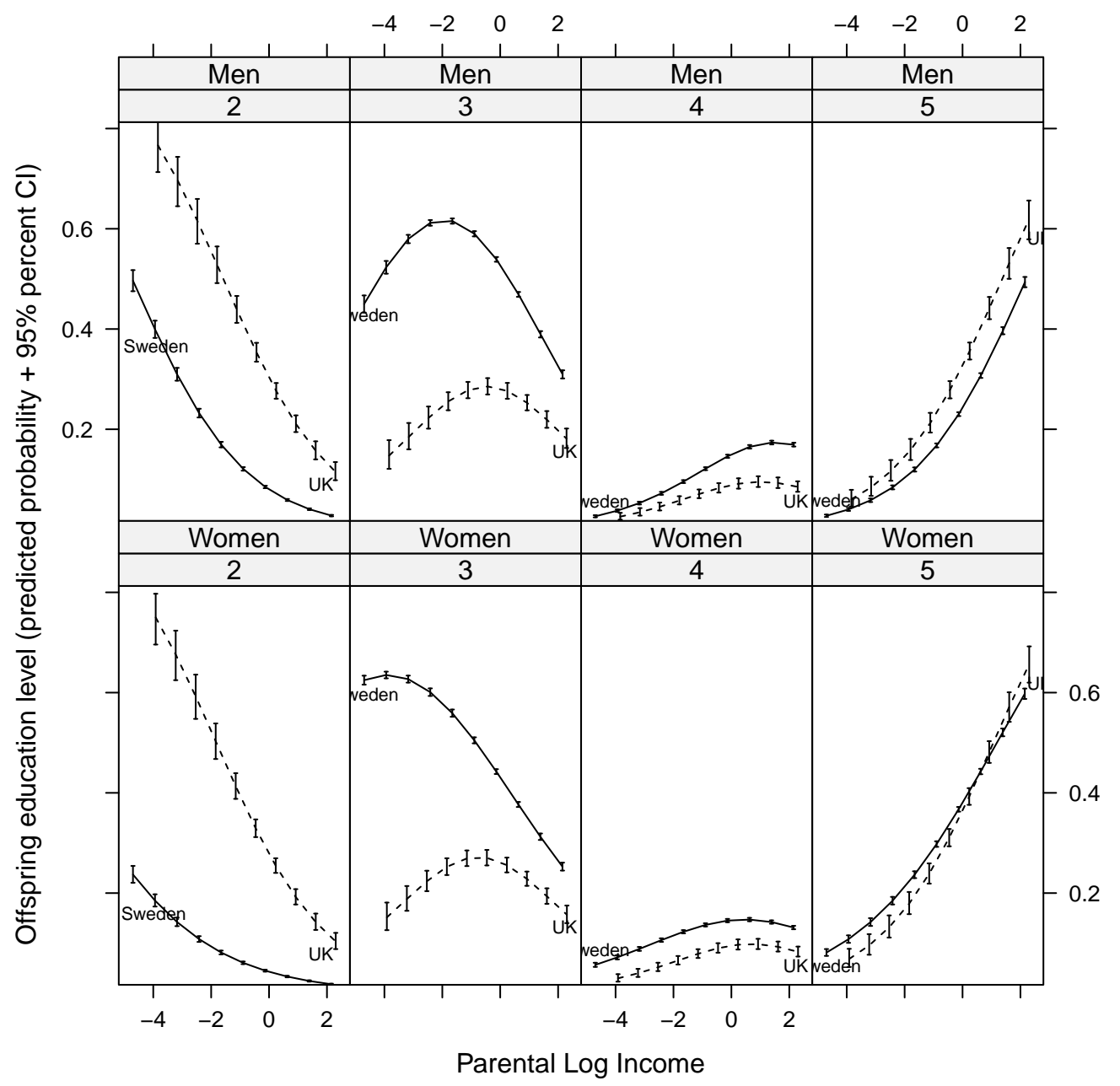

Note: Graph shows the gradient of probability of different final education outcomes (i.e., ISCED 2, 3, 4, and 5) of the offspring with respect to standardized log parental income. 
explore this we use a straightforward analytical framework that distinguishes between, on the one hand, the intergenerational covariances between parental income and the productivity traits, and, on the other hand, the returns to these productivity traits. ${ }^{13}$

Denote a single productivity trait for the child generation by $X^{c}$, and the relevant income measures for parents and children by $Y^{p}$ and $Y^{c}$, respectively. We make use of a linear regression of the child's earnings on each productivity trait that we study, for example

$$
Y^{c}=\alpha+\beta X^{c}+\epsilon
$$

where $X^{c}$ in the first case represents birth weight. Using equation (1) and $Y^{p}$, the estimated intergenerational income elasticity (IGE) becomes

$$
\mathrm{IGE}=\operatorname{Cov}\left(Y^{p}, Y^{c}\right) / \sigma^{2}=\beta \operatorname{Cov}\left(Y^{p}, X^{c}\right) / \sigma^{2}+\operatorname{Cov}\left(Y^{p}, \epsilon\right) / \sigma^{2},
$$

where $\sigma^{2}$ denotes the variance of parental income. By dividing $Y^{p}$ and $Y^{c}$ by their respective standard deviations, we instead obtain a decomposition of the intergenerational income correlation (IGC).

We can examine the contribution of each of our productivity traits to the intergenerational income correlation by estimating equation (1), retrieving the residuals, and computing the components of equation (2). It is the first component - the product of the monetary return to the trait and the covariance between the trait and parental income - that can be attributed to the trait we consider, whereas the second component represents everything else. We can also separately examine the importance of the monetary returns $\beta$ and the intergenerational covariance between parental income and the trait.

In Table 5, we report the results from this accounting exercise for Sweden and the UK. ${ }^{14}$ We restrict the analysis to sons. Neither birth weight nor height - our measures of early childhood and late teen health traits - can account for hardly anything of the Sweden-UK difference in the IGC. We can see that the component that is attributed to these traits is very small compared to the total correlation in both the countries. Thus, the small absolute cross-national difference in the component cannot explain a substantial part of the countrynational difference in the IGC.

\footnotetext{
${ }^{13}$ For similar exercises, see Österbacka (2001) and Björklund et al. (2005).

${ }^{14}$ Note that the IGCs differ slightly from the ones in Table 2. The reason is that we have estimated the IGCs in Table 5 on samples that also contain valid measures of the respective traits.
} 


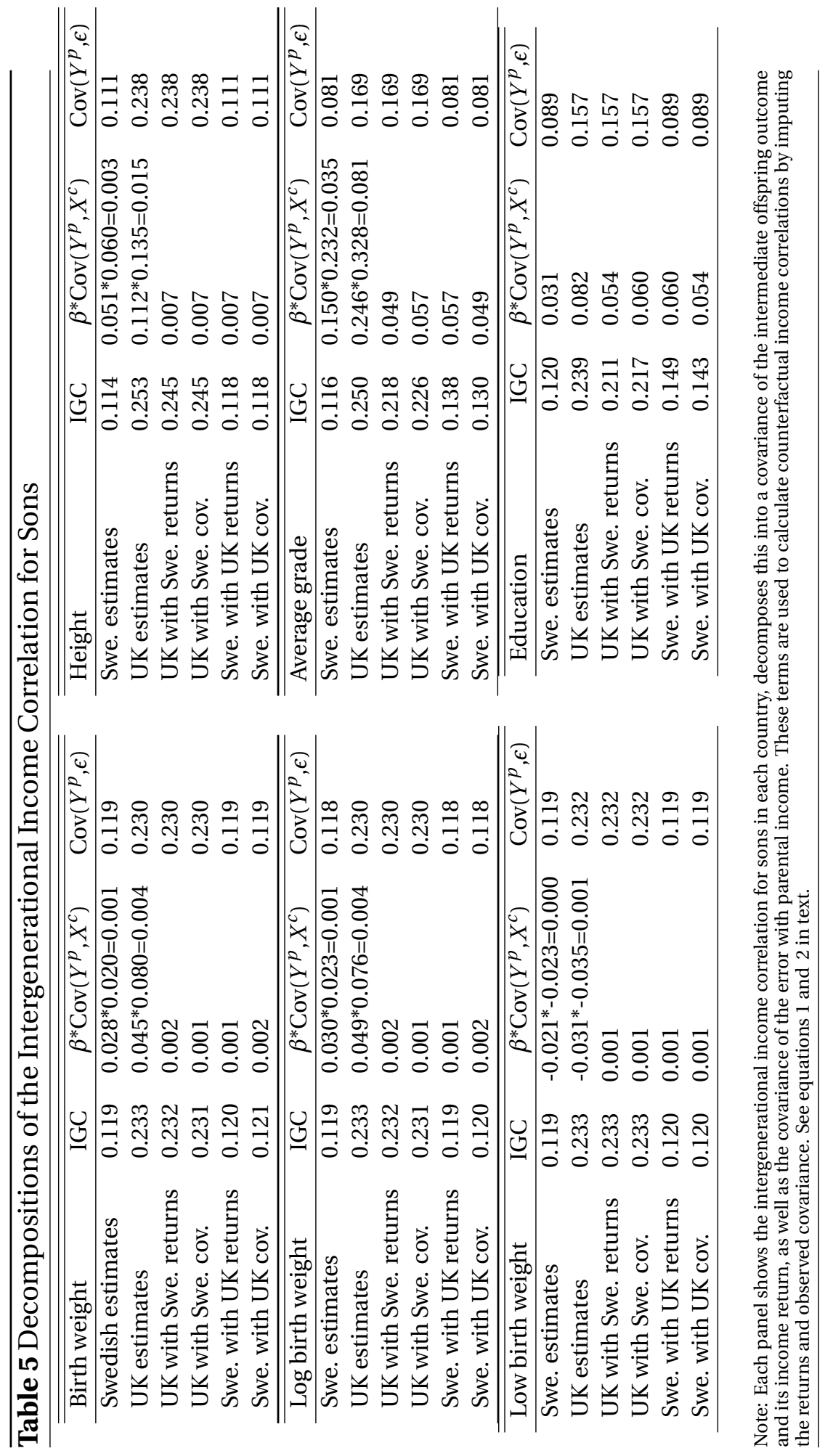


When we turn to grades, another pattern emerges. First, we see that the components attributed to grades make up about one third of the IGC in both countries. In absolute terms, this component is .081 for the UK and .035 for Sweden. Thus, one can say that .046 (=.081-.035) of the cross-national difference can be attributed to factors associated with grades at age 16 . When considering this difference, it is interesting to look separately at the contributions of the monetary returns to grades $(\beta)$ and the covariance between the trait and parental income. The country difference obviously pertains about equally to both these components, with a slightly higher contribution from the monetary return. When we let Sweden have the UK return, its IGC goes up to .138 (from .116), and when we let Sweden have the UK covariance it goes up to .130. Similarly, when we let the UK have the Swedish return, its IGC goes down to .218 (from .250), and when we let the UK have the Swedish covariance it goes down to 226 .

Finally, we have the results for education. For this outcome, the component attributed to the trait also makes up about one third of the total IGC. However, the UK IGC is not reduced that much neither by giving the UK the Swedish return nor by giving the UK the Swedish covariance. The Swedish IGC, in turn, goes up more with UK returns than with the UK covariances (from .120 to .149 and .143, respectively). The results are consequently somewhat mixed for education.

\section{Robustness Checks}

So far we have used the largest possible sample for each separate analysis. By so doing, we have maximized the precision and minimized the sample selection bias for each estimated parameter. It could, however, be argued that our comparisons of the relative importance of different traits becomes flawed by the fact that we compare estimates from different samples. Therefore, we have also reestimated all parameters in Table 4 and the decompositions in Table 5 on balanced samples. The requirement that all variables are simultaneously available reduces the samples by some 10 percent for Sweden, but from 3153 to 1511 for UK daughters and from 3304 to 719 for UK sons. As a consequence, the precision of the estimates falls. However, the main pattern of the results remain the same. The differences between the intergenerational income associations in Table 2 remain about the same. The country differences in the parameters of the trait variables are also the same except for height which are no longer sig- 
nificantly different across the two countries. The decompositions reported in Table 5 also tell the same story with the balanced sample. A full set of estimates based on the balanced sample is available from the authors upon request.

To ensure comparability across countries, we used the Swedish data on parental income in the same way as for the UK, i.e., by dividing the data into intervals of the parental income distribution and using the center values in each interval. We briefly examine the sensitivity of the results to this particular feature of the data by comparing our main results with results from using the actual data (i.e., continuous measures for Sweden). We report descriptive statistics and estimates for this sensitivity analysis in Appendix Table A. 1. The discrepancies are small and do not affect any of our conclusions.

\section{Conclusions}

We have presented an approach to exploring the mechanisms behind crossnational differences in intergenerational income transmission. We applied this approach on data from Sweden and the UK, but we think that it can serve as a model also for other cross-national comparisons.

We first explored the importance of two variables that have received much attention in recent research by economists, namely birth weight and height during adolescence. Although we found a significant cross-national difference in the association between these traits and parental income, only a trivial magnitude of the intergenerational income correlation (and the country difference in this correlation) could be attributed to these traits. The product of the monetary return in adulthood to these traits and the covariance between these traits and parental income were simply too small to be important for the observed intergenerational mobility parameters. This is not to say that early childhood is not important for intergenerational income mobility, but our results suggest that these variables do not capture enough of important mechanisms.

When we turned to the more conventional human-capital variables, grades and final education, the results were different. Especially for grades at the end of compulsory school, we found that factors associated with this variable could account for about a third of the intergenerational income correlation. Further, a substantial part of the country difference in intergenerational income mobility could be accounted for by such factors. Nonetheless, it was striking that the higher monetary return to grades in the UK labor market compared to the Swedish was the most important factor behind this result. 
Although our results do not prove that differences in early childhood circumstances are not important for cross-national differences in intergenerational income mobility, they suggest that future research should look broadly for possible determinants of these differences. The labor market strikes us as an important arena with lots of mechanisms that can explain these differences. 


\section{References}

Becker, G. S., And N. Tomes (1979): "An Equilibrium Theory of the Distribution of Income and Intergenerational Mobility," The Journal of Political Economy, 87(6), 1153-1189.

(1986): "Human Capital and the Rise and Fall of Families," Journal of Labor Economics, 4(3), S1-39.

BÖHLMARK, A., AND M. J. Lindquist (2006): "Life-Cycle Variations in the Association between Current and Lifetime Income: Replication and Extension for Sweden," Journal of Labor Economics, 24(4), 879-896.

Björklund, A., M. Clark, P.-A. Edin, P. Fredriksson, and A. B. Krueger (2005): The Market comes to Education in Sweden: an Evaluation of Sweden's Surprising School Reforms. Russell Sage Foundation, New York.

BJÖRKLUND, A., AND M. JÄNTTI (2009): “Intergenerational income mobility and the role of family background," in Oxford Handbook of Economic Inequality, ed. by W. Salverda, B. Nolan, and T. M. Smeeding, chap. 20, pp. 491-521. Oxford University Press, Oxford.

BJÖRKLUnd, A., M. JÄNTTI, AND M. NyBOM (2012): "Parental education gradients over the life cycle," in From Parents to Children: The Intergenerational Transmission of Advantage, ed. by J. Ermisch, M. Jäntti, and T. Smeeding, chap. 17, pp. 422-440. Russell Sage Foundation, New York.

BJÖRKLUnd, A., M. Lindahl, AND K. Sund (2003): "Family background and school performance during a turbulent era of school reforms," Swedish Economic Policy Review, 10(2), 111-136.

Black, S. E., P. J. DevereuX, and K. G. Salvanes (2007): "From the Cradle to the Labor Market? The Effect of Birth Weight on Adult Outcomes," Quarterly Journal of Economics, 122(1), 409-439.

BLANDEN, J. (2013): "Cross-country rankings in intergenerational mobility: A comparison of approaches in economics and sociolog," Journal of Economic Surveys, Forthcoming.

Blanden, J., A. Goodman, P. Gregg, and S. Machin (2004): "Changes in intergenerational mobility in Britain," in Generational Income Mobility in 
North America and Europe, ed. by M. Corak, chap. 6, pp. 122-146. Cambridge University Press, Cambridge.

Borghans, L., B. Golsteyn, J. Heckman, and J. Humphries (2011): "Identification Problems in Personality Psychology," Personality and Individual Differences, 51(3), 315-320.

CASE, A., AND C. PAXSON (2008): "Stature and Status: Height, Ability, and Labor Market Outcomes,” Journal of Political Economy, 116(3), 499-532.

CORAK, M. (2006): "Do poor children become poor adults? Lessons for public policy from a cross country comparison of generational earnings mobility," Discussion Paper 1993, IZA, Bonn.

CORAK, M., AND P. PiRAINO (2011): "The Intergenerational Transmission of Employers and Earnings,” Journal of Labor Economics, 29(1), 37-68.

Currie, J. (2009): "Healthy, Wealthy, and Wise: Socioeconomic Status, Poor Health in Childhood, and Human Capital Development," Journal of Economic Literature, 47(1), 87-122.

Erikson, R., J. Goldthorpe, M. Jackson, M. Yaish, and D. Cox (2005): “On class differentials in educational attainment," Proceedings of the National Academy of Sciences, 102(27), 9730-33.

Jäntti, M., B. Bratsberg, K. Røed, O. RaAum, R. Naylor, E. Österbacka, A. BJÖRKLUND, AND T. ERIKSSON (2006): "American exceptionalism in a new light: a comparison of intergenerational earnings mobility in the Nordic countries, the United Kingdom and the United States," Discussion Paper 1938, IZA, Bonn.

Lundborg, P., P. Nystedt, and D.-O. Rooth (2009): “The Height Premium in Earnings: The Role of Physical Capacity and Cognitive and Non-Cognitive Skills,” Discussion Paper 4266, IZA, Bonn, http://ftp.iza.org/dp4266.pdf.

MAZumDeR, B. (2005): "Fortunate Sons: New Estimates of Intergenerational Mobility in the United States Using Social Security Earnings Data," Review of Economics and Statistics, LXXXVII(2), 235-255.

Nybom, M., AND J. STUhler (2011): "Heterogeneous Income Profiles and LifeCycle Bias in Intergenerational Mobility Estimation,” Discussion Paper 5697, IZA, Bonn, http://ftp.iza.org/dp5697.pdf. 
SolON, G. (2004): "A Model of Intergenerational Mobility Variation over Time and Place," in Generational Income Mobility in North America and Europe, ed. by M. Corak, chap. 2, pp. 38-47. Cambridge University Press, Cambridge.

SolON, G. M. (2002): “Cross-country Differences in Intergenerational Earnings Mobility,” Journal of Economic Perspectives, 16(3), 59-66.

ÖsterbaCKA, E. (2001): "Family background and economic status in Finland," Scandinavian Journal of Economics, 103(3), 467-484. 


\section{Appendix}

\section{A.1 Continuous Parental Income Data for Sweden}

Table A. 1 Descriptives and Estimates of Intergenerational Income Associations - Continuous Parental Income for Sweden

\begin{tabular}{|c|c|c|c|c|c|c|c|c|c|}
\hline \multicolumn{10}{|c|}{ A. Descriptives } \\
\hline & & & \multicolumn{3}{|c|}{ Sons } & \multicolumn{3}{|c|}{ Daughters } & \\
\hline & & & \multicolumn{2}{|c|}{ Sweden } & UK & \multicolumn{2}{|c|}{ Sweden } & UK & \\
\hline \multicolumn{3}{|c|}{ Log earnings, offspring } & \multicolumn{2}{|c|}{$\begin{array}{l}6.25 \\
(0.77)\end{array}$} & $\begin{array}{l}6.57 \\
(0.61)\end{array}$ & \multicolumn{2}{|c|}{$\begin{array}{l}5.93 \\
(0.76)\end{array}$} & \multicolumn{2}{|c|}{$\begin{array}{l}5.98 \\
(0.87)\end{array}$} \\
\hline \multicolumn{3}{|c|}{ Log income, parents } & \multicolumn{2}{|c|}{$\begin{array}{l}6.51 \\
(0.50)\end{array}$} & $\begin{array}{l}6.18 \\
(0.51)\end{array}$ & \multicolumn{2}{|c|}{$\begin{array}{l}6.52 \\
(0.50)\end{array}$} & \multicolumn{2}{|c|}{$\begin{array}{l}6.20 \\
(0.51)\end{array}$} \\
\hline \multicolumn{3}{|l|}{ Parental age } & \multicolumn{2}{|c|}{$\begin{array}{l}40.80 \\
(4.99)\end{array}$} & $\begin{array}{c}39.45 \\
(5.77)\end{array}$ & \multicolumn{2}{|c|}{$\begin{array}{c}40.73 \\
(5.00)\end{array}$} & \multicolumn{2}{|c|}{$\begin{array}{c}39.49 \\
(5.75)\end{array}$} \\
\hline \multicolumn{3}{|c|}{ Fraction with two parents } & \multicolumn{2}{|c|}{0.88} & 0.93 & \multicolumn{2}{|c|}{0.87} & \multicolumn{2}{|c|}{0.93} \\
\hline $\mathrm{n}$ & & & \multicolumn{2}{|c|}{48424} & 3304 & \multicolumn{2}{|c|}{44414} & \multicolumn{2}{|c|}{3153} \\
\hline \multicolumn{10}{|c|}{ B. Estimates } \\
\hline & \multicolumn{5}{|c|}{ Sons } & \multicolumn{4}{|c|}{ Daughters } \\
\hline & Sweden & & $\mathrm{K}$ & \multicolumn{2}{|c|}{ F-test } & Sweden & \multicolumn{2}{|c|}{ UK } & F-test \\
\hline Regression coef & $\begin{array}{l}0.186 \\
(0.007)\end{array}$ & & & $\begin{array}{r}6 . \\
{[0.0}\end{array}$ & & $\begin{array}{l}0.167 \\
(0.007)\end{array}$ & $\begin{array}{l}0.3 \\
(0.0\end{array}$ & & $\begin{array}{c}36.4 \\
{[0.000]}\end{array}$ \\
\hline Correlation & $\begin{array}{l}0.120 \\
(0.005)\end{array}$ & & & $\begin{array}{l}28 \\
{[0.0}\end{array}$ & & $\begin{array}{l}0.108 \\
(0.005)\end{array}$ & $\begin{array}{l}0.1 \\
(0.0\end{array}$ & & $\begin{array}{l}22.8 \\
{[0.000]}\end{array}$ \\
\hline Quadratic (lin) & $\begin{array}{c}-0.143 \\
(0.054)\end{array}$ & & $\begin{array}{l}956 \\
\text { e97) }\end{array}$ & 8. & & $\begin{array}{c}-0.144 \\
(0.062)\end{array}$ & & $\begin{array}{l}835 \\
30)\end{array}$ & $\begin{array}{c}6.0 \\
{[0.014]}\end{array}$ \\
\hline (sq.) & $\begin{array}{l}0.027 \\
(0.004)\end{array}$ & & & & & $\begin{array}{l}0.025 \\
(0.005)\end{array}$ & & 96 & \\
\hline
\end{tabular}

Note: Estimates correspond to specifications in Tables 1 and 2 except that these rely on continuous rather than grouped parental income as the regressor for Sweden. Standard errors are within parentheses and p-values within brackets. 